\title{
Effect of Voxel Size on Detection of External Root Resorption Defects Using Cone Beam Computed Tomography
}

\author{
Sima Nikneshan, ${ }^{1}$ Solmaz Valizadeh, ${ }^{1}$ Anahita Javanmard ${ }^{2}$ and Leila Alibakhshi ${ }^{1,}{ }^{*}$ \\ ${ }^{1}$ Department of Radiology, School of Dentistry, Shahid Beheshti University of Medical Sciences, Tehran, Iran \\ ${ }^{2}$ Dentist, Tehran, Iran \\ "Corresponding author: Leila Alibakhshi, Department of Radiology, School of Dentistry, Shahid Beheshti University of Medical Sciences, Tehran, Iran. Tel: +98-2122907040, Fax: \\ +98-2188804037, E-mail: Alibakhshi_1@yahoo.com
}

Received 2015 November 23; Revised 2016 February 28; Accepted 2016 March 26

\begin{abstract}
Background: Selecting a voxel size that yields minimal radiation dose with no significant compromise of the diagnostic accuracy of cone beam computed tomography (CBCT) is particularly important.

Objectives: This study aimed to assess the effect of voxel size on detection accuracy of simulated external root resorption defects using NewTom CBCT system.

Materials and Methods: In this diagnostic study, the roots of 90 extracted human central incisors were hypothetically divided into cervical, middle, and apical thirds. Variable-size defects were prepared in the buccal and lingual surfaces of the roots and CBCT scans were obtained with four different voxel sizes $(150,200,250$, and 300). Presence or absence of defects on CBCT scans was determined by three radiologists and the results were compared with the gold standard (actual size and depth of defects). Sensitivity and specificity values were calculated and reported for different groups.

Results: In the lingual surfaces, the highest specificity and sensitivity belonged to $300 \mu \mathrm{m}$ voxel size (92.9\%), and 200 and $250 \mu \mathrm{m}$ voxel sizes (both 97.4\%) in the cervical third, respectively. In the middle third, the highest specificity and sensitivity belonged to 250 and $200 \mu \mathrm{m}$ voxel sizes ( $84.6 \%$ and $100 \%$, respectively). In the apical third, the highest specificity and sensitivity belonged to $300 \mu \mathrm{m}$ voxel size (100\% and $97.9 \%$, respectively). In the buccal surfaces, the highest specificity and sensitivity belonged to 150 (75.0\%), 300 and $250 \mu \mathrm{m}$ voxel sizes (100\%) and the minimum values belonged to $200 \mu \mathrm{m}$ voxel size (60\% and 97.3\%) in the cervical third. In the apical third, the highest specificity and sensitivity were noted in $300 \mu \mathrm{m}$ voxel size $(100 \%$ and $97.6 \%$, respectively) and the minimum values were seen in 200 and $150 \mu \mathrm{m}$ voxel sizes (93.8\%, 90.5\%, respectively). In the middle third, 300, 250 and $200 \mu \mathrm{m}$ voxel sizes yielded the highest specificity (88.9\%), while $150 \mu$ m voxel size yielded the highest sensitivity (98.8\%).

Conclusion: Considering the similar diagnostic efficacy of all voxel sizes, $300 \mu \mathrm{m}$ voxel size can be used with adequate efficacy for detection of external root resorption defects with minimal patient radiation dose and the shortest scanning time.
\end{abstract}

Keywords: Accuracy, Cone-Beam Computed Tomography, Root Resorption

\section{Background}

External root resorption is an irreversible, multifactorial process that may lead to tooth loss (1). External root resorption in non-traumatized primary teeth is part of a physiological process to replace the primary teeth with their permanent successors. However, root resorption may also occur as a pathological process. It may also occur following orthodontic tooth movement, dental trauma, pulp infections, bleaching or periodontal disease. Moreover, impacted teeth, cysts, tumors and pressure of erupting canines applied to lateral incisors may cause external root resorption $(2,3)$. If diagnosed early and the causative agent is eliminated, the resorbed area may be restored followed by cementum deposition. Thus, early detection of external root resorption is necessary for a prompt treatment. To date, no general protocol has been defined for CBCT for spe- cific diagnostic tasks in dentistry (4).

External root resorption is diagnosed by clinical and radiographic examinations (5). However, use of conventional radiography for this purpose results in false negative results in $51.9 \%$ and false positive results in $15.3 \%$ of cases (6). The CBCT technology aids the diagnosis of endodontic pathosis and analysis of resorption defects (7). Defects smaller than $0.6 \mathrm{~mm}$ in diameter and less than $0.3 \mathrm{~mm}$ in depth are not detectable on conventional periapical radiographs; this results in under-diagnosis and progression of root resorption $(8,9)$. Radiographic detection of external root resorption on buccal and lingual root surfaces is a real challenge (10). In 2007, Da Silveira et al. conducted a study on the elimination of superimposition of structures to improve the detection accuracy of resorption defects. This study showed that axial multislice com- 
puted tomography (CT) had a high diagnostic sensitivity and excellent specificity for detection of simulated defects in the buccal surfaces of teeth (except for small defects located in the apical third) (11).

On the other hand, diagnostic efficacy and correct estimation of the position and size of root resorption defects are critical factors for selection of an appropriate treatment plan and achieving a successful outcome (9). Thus, three-dimensional (3D) images may serve as important diagnostic tools in dental treatments. Use of CBCT scans can greatly help in this regard due to advantages such as the use of collimator that limits the radiation from the X-ray tube to a specific area, use of convergent voxels that enable image reconstruction of dental structures with an original quality, high speed (10 to 70 seconds) and low patient radiation dose (approximately 1/60 of that of multislice CT) (12-14). Accuracy of measurements using CBCT was comparable with those made on dry mandible (15). In CBCT, data acquisition is done via the rotation of X-ray beam around an object that gradually moves forward. On the other hand, voxel size in this technique has a direct correlation with the quality of the image and the exposure dose. In a study performed by Liedke et al. in 2009, CBCT was reported to be valid for detection of simulated external root resorption defects and $0.3 \mathrm{~mm}$ voxel size yielded the highest diagnostic accuracy and the least patient radiation dose (16). In their study, no correlation was noted between voxel size (0.2, 0.3 and $0.4 \mathrm{~mm}$ ) and tomographic plane (axial, frontal, sagittal), size of defect (small, medium, large) or position of defects (apical, middle or cervical third of the root). Moreover, sensitivity and specificity of CBCT were equal for all voxel sizes. In another study conducted by Patel et al. in 2009, CBCT was found to be a valid and reliable technique for estimation of presence or absence of root resorption compared to intraoral digital radiography (17). Thus, considering the advantages of CBCT, it may enable early detection of internal and external root resorption and improve the prognosis of treatment.

Researchers are searching for dental imaging techniques with high diagnostic accuracy and low patient radiation dose to enhance diagnosis and decrease possible side effects of radiation.

\section{Objectives}

Considering the importance of early detection of external root resorption, this study sought to assess the effect of voxel size on detecting external root resorption using NewTom CBCT system.

\section{Materials and Methods}

This diagnostic study was conducted on 90 extracted sound human mandibular central incisors. The teeth had been extracted due to periodontal disease (hopeless prognosis) or upon patient's demand for a complete denture. Sample size was calculated to be 90 considering $80 \%$ power of study and type 1 error of 0.05 using the sample size calculation formula and also based on previous studies $(16,18)$.

Sampling was non-randomized but variable-size defects were created randomly in the cervical, middle, and apical thirds of the roots. The teeth were visually inspected to ensure they were sound. After collection, the teeth were immersed in a solution of sodium hypochlorite in water ( $1 / 5$ ratio) and were then immersed in $70 \%$ alcohol. The teeth were randomly coded from 1 to 90 . The roots were hypothetically (without sectioning) divided into cervical, middle, and apical thirds and a total of 450 regions were obtained as such. In each region, a defect was created or the region remained intact as a control site. For each region, four possibilities existed with regard to cavity preparation:

1. Small defect ( $0.3 \mathrm{~mm}$ in depth and $0.6 \mathrm{~mm}$ in diameter)

2. Medium defect $(0.6 \mathrm{~mm}$ in depth and $1.2 \mathrm{~mm}$ in diameter)

3. Large defect $(0.9 \mathrm{~mm}$ in depth and $1.8 \mathrm{~mm}$ in diameter)

4. No defect (control)

Therefore, 90 teeth were selected to simulate all possibilities of occurrence of external root resorption defects in the clinical setting. To simulate external root resorption defects, cavities were prepared by a round bur. Defects were created in the buccal and lingual root surfaces by 0.6 , 1.2 , and $1.8 \mathrm{~mm}$ round diamond burs. When preparing the defects, the bur shank was positioned tangent to the root to ensure maximum precision in preparing the defects. To ensure the accurate size of the defects, dimensions were measured by a digital caliper. Defects were randomly prepared in the cervical, middle, and apical thirds. To simulate the periodontal ligament (PDL), roots were coated with a $0.2 \mathrm{~mm}$-thick layer of wax using the dipping method to the level of the cementoenamel junction (Figure 1)(16). Six wax molds were formed in the form of the mandibular arch, then filled with a mixture of plaster and sawdust, and 15 teeth were mounted in each mold (Figure 2). Next, CBCT scans were obtained of each mold with sagittal, frontal and axial slices using four different voxel sizes of 150, 200, 250, and $300 \mu \mathrm{m}$ (NewTom VGi, QR SRL Company, Verona, Italy). The reason for selecting these voxel sizes was because root resorption defects are very small, and the smaller the voxel size, the higher the odds of visualization of smaller de- 
fects. Also, selection of these voxel sizes was based on previous studies $(16,18)$. To obtain radiographs, molds were placed in a container filled with water to simulate soft tissue. Qualitative and quantitative indices for presence or absence of defects and size of defects were evaluated by three radiologists who were blinded to the group allocation of specimens using the NewTom software (Figure 3). To assess intra-observer agreement, the same observers evaluated the samples again after 15 days. The observers were allowed to use all features of NewTom software. Data were recorded in data sheets and compared with the gold standard. The gold standard values were recorded earlier when the defects were being preparing.

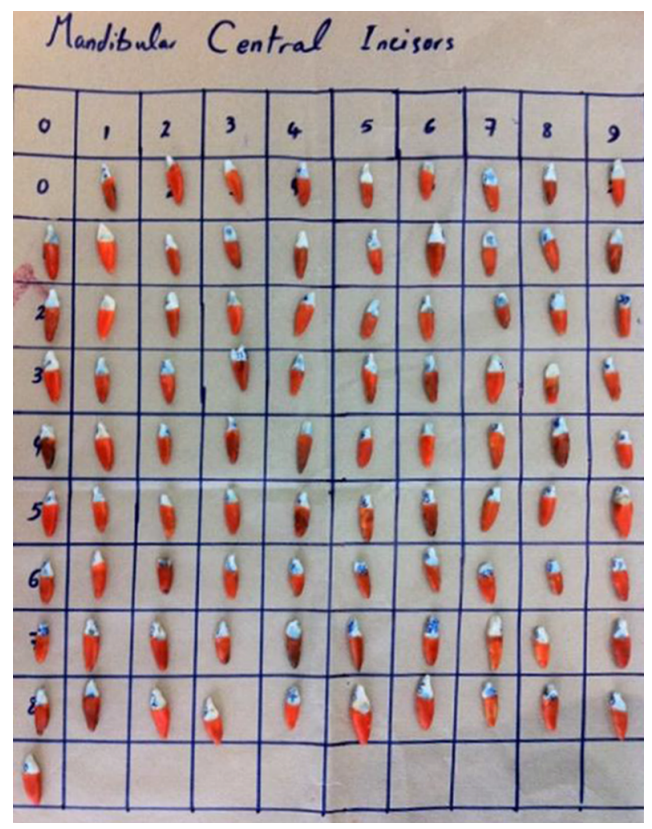

Figure 1. The teeth after wax coating

The agreement of diagnoses of simulated external root resorption defects with the gold standard was evaluated based on voxel size, defect size, presence of defect in the buccal or lingual root surface, and cervical, middle or apical third of the root and reported using descriptive statistics (number and percentage). The actual size and depth of defects created on the root surfaces (namely no cavity, small cavity, medium cavity, and large cavity) were considered as the gold standard. Also, sensitivity and specificity of diagnoses based on each of the above-mentioned parameters were calculated and reported. The data were analyzed using SPSS version 22 software (Microsoft, IL, USA). The Kappa coefficient for the three observers was calculated as 1 . The proportion test was used to compare sensitivity and specificity values among different voxel sizes.

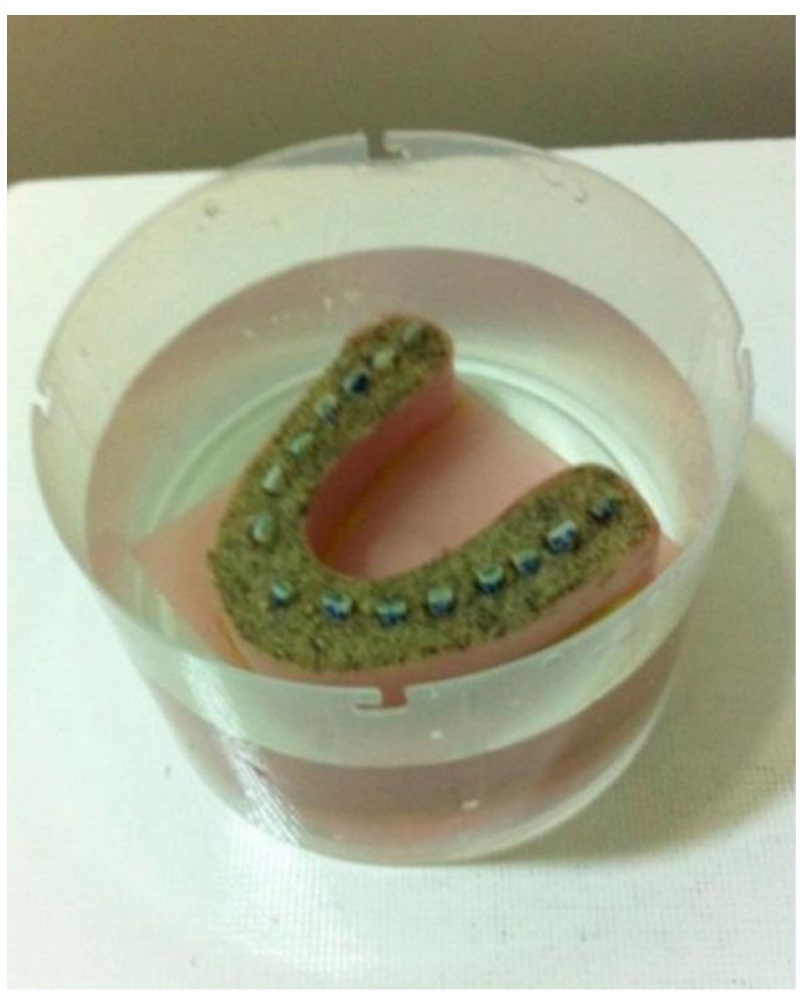

Figure 2. The teeth were mounted in molds filled with plaster and sawdust and immersed in water to simulate soft tissue.

\section{Results}

Assessment of the agreement of diagnoses with the gold standard (Tables 1 and 2 ) revealed that in the cervical third of the lingual surfaces of the roots, the highest specificity belonged to $300 \mu \mathrm{m}$ voxel size (92.9\%), and the lowest to $150 \mu \mathrm{m}$ voxel size $(64.3 \%)(\mathrm{P}=0.198)$. In this group, the highest sensitivity belonged to 200 and $350 \mu \mathrm{m}$ voxel sizes (97.4\%) and the lowest to $300 \mu \mathrm{m}$ voxel size (94.7\%) (P $=0.920$ ) (Table 3 ).

In the middle third of the lingual surfaces of the roots, the highest specificity belonged to 200 and $250 \mu \mathrm{m}$ voxel sizes (84.6\%) and the lowest to 150 and $300 \mu \mathrm{m}$ voxel sizes (76.9\%) $(\mathrm{P}=0.518)$. In this group, the highest sensitivity belonged to 200 and $250 \mu \mathrm{m}$ voxel sizes (100\%) and the lowest to 150 and $300 \mu \mathrm{m}$ voxel sizes $(98.7 \%)(\mathrm{P}=0.953)$ (Table 3$)$.

In the apical third of the lingual surfaces of the roots, the highest specificity belonged to $300 \mu \mathrm{m}$ voxel size $(100 \%)$ and other voxel sizes showed equal specificity (92.9\%) $(\mathrm{P}=0.883)$. In this group, the highest sensitivity belonged to $300 \mu \mathrm{m}$ voxel size (97.9\%) and the lowest to 200 $\mu \mathrm{m}$ voxel size $(93.8 \%)(\mathrm{P}=0897)$ (Table 3$)$.

In the cervical third of the buccal surfaces of the roots, the highest specificity belonged to $150 \mu \mathrm{m}$ voxel size 
Table 1. Agreement of Diagnoses with the Gold Standard Based on the Size of Defects in the Buccal Root Surfaces Using Different Voxel Sizes (16, 18)

\begin{tabular}{|c|c|c|c|c|c|c|c|c|c|c|c|c|c|c|c|c|c|c|c|c|c|}
\hline \multirow{3}{*}{$\begin{array}{l}\text { Anatom- } \\
\text { ical } \\
\text { Part }\end{array}$} & \multirow{3}{*}{$\begin{array}{c}\text { Diag- } \\
\text { nosed } \\
\text { De- } \\
\text { fect } \\
\text { Size }\end{array}$} & \multicolumn{20}{|c|}{ Voxel Sizes } \\
\hline & & \multicolumn{20}{|c|}{ Gold Standard Defect Size } \\
\hline & & $\begin{array}{l}\text { No } \\
\text { De- } \\
\text { fect }\end{array}$ & $\begin{array}{l}\text { Small } \\
\text { De- } \\
\text { fect }\end{array}$ & $\begin{array}{c}\text { Medium } \\
\text { De- } \\
\text { fect }\end{array}$ & $\begin{array}{l}\text { Large } \\
\text { De- } \\
\text { fect }\end{array}$ & Total & $\begin{array}{l}\text { No } \\
\text { De- } \\
\text { fect }\end{array}$ & $\begin{array}{l}\text { Small } \\
\text { De- } \\
\text { fect }\end{array}$ & $\begin{array}{c}\text { Medium } \\
\text { De- } \\
\text { fect }\end{array}$ & $\begin{array}{l}\text { Large } \\
\text { De- } \\
\text { fect }\end{array}$ & Total & $\begin{array}{l}\text { No } \\
\text { De- } \\
\text { fect }\end{array}$ & $\begin{array}{l}\text { Small } \\
\text { De- } \\
\text { fect }\end{array}$ & $\begin{array}{c}\text { Medium } \\
\text { De- } \\
\text { fect }\end{array}$ & $\begin{array}{l}\text { Large } \\
\text { De- } \\
\text { fect }\end{array}$ & Total & $\begin{array}{l}\text { No } \\
\text { De- } \\
\text { fect }\end{array}$ & $\begin{array}{l}\text { Small } \\
\text { De- } \\
\text { fect }\end{array}$ & $\begin{array}{c}\text { Medium } \\
\text { De- } \\
\text { fect }\end{array}$ & $\begin{array}{l}\text { Large } \\
\text { De- } \\
\text { fect }\end{array}$ & Total \\
\hline \multirow{4}{*}{$\begin{array}{l}\text { Cervical } \\
\text { Third }\end{array}$} & $\begin{array}{l}\text { No } \\
\text { De- } \\
\text { fect }\end{array}$ & 11 & 0 & 0 & 0 & 11 & 11 & 0 & 0 & 0 & 11 & 9 & 1 & 0 & 1 & 11 & 9 & 0 & 1 & 1 & 11 \\
\hline & $\begin{array}{c}\text { Small } \\
\text { De- } \\
\text { fect } \\
\end{array}$ & 5 & 18 & 4 & 0 & 27 & 3 & 21 & 3 & 0 & 27 & 3 & 19 & 4 & 1 & 27 & 1 & 26 & 0 & 0 & 27 \\
\hline & $\begin{array}{l}\text { Medium } \\
\text { De- } \\
\text { fect }\end{array}$ & 1 & 5 & 15 & 0 & 21 & 0 & 6 & 15 & 0 & 21 & 1 & 7 & 13 & 0 & 21 & 1 & 8 & 12 & 0 & 21 \\
\hline & Total & 17 & 23 & 19 & 31 & 90 & 16 & 27 & 19 & 28 & 90 & 15 & 27 & 17 & 31 & 90 & 12 & 36 & 14 & 28 & 90 \\
\hline \multirow{5}{*}{$\begin{array}{l}\text { Middle } \\
\text { Third }\end{array}$} & $\begin{array}{l}\text { No } \\
\text { De- } \\
\text { fect }\end{array}$ & 8 & 1 & 0 & 0 & 9 & 8 & 1 & 0 & 0 & 9 & 8 & 1 & 0 & 0 & 9 & 7 & 2 & 0 & 0 & 9 \\
\hline & $\begin{array}{l}\text { Small } \\
\text { De- } \\
\text { fect }\end{array}$ & 2 & 21 & 1 & 0 & 24 & 2 & 19 & 2 & 1 & 24 & 2 & 21 & 1 & 0 & 24 & 1 & 21 & 1 & 1 & 24 \\
\hline & $\begin{array}{l}\text { Medium } \\
\text { De- } \\
\text { fect } \\
\end{array}$ & 0 & 5 & 14 & 0 & 19 & 0 & 5 & 13 & 1 & 19 & 0 & 2 & 15 & 2 & 19 & 0 & 7 & 11 & 1 & 19 \\
\hline & $\begin{array}{l}\text { Large } \\
\text { De- } \\
\text { fect }\end{array}$ & 0 & 0 & 1 & 37 & 38 & 0 & 1 & 4 & 33 & 38 & 0 & 3 & 3 & 32 & 38 & 0 & 2 & 2 & 34 & 38 \\
\hline & Total & 10 & 27 & 16 & 37 & 90 & 10 & 26 & 19 & 35 & 90 & 10 & 27 & 19 & 34 & 90 & 8 & 32 & 14 & 36 & 90 \\
\hline \multirow{4}{*}{$\begin{array}{l}\text { Apical } \\
\text { Third }\end{array}$} & $\begin{array}{l}\text { No } \\
\text { De- } \\
\text { fect }\end{array}$ & 48 & o & 0 & 0 & 48 & 47 & 0 & 0 & 1 & 48 & 45 & 1 & 0 & 2 & 48 & 45 & 1 & 0 & 2 & 48 \\
\hline & $\begin{array}{l}\text { Medium } \\
\text { De- } \\
\text { fect }\end{array}$ & 0 & 4 & 14 & 0 & 18 & 0 & 8 & 10 & 0 & 18 & 0 & 7 & 11 & 0 & 18 & 0 & 9 & 9 & 0 & 18 \\
\hline & $\begin{array}{l}\text { Large } \\
\text { De- } \\
\text { fect }\end{array}$ & 0 & 0 & 0 & 7 & 7 & 2 & 0 & 0 & 5 & 7 & 2 & 0 & 0 & 5 & 7 & 2 & 0 & 0 & 5 & 7 \\
\hline & Total & 49 & 20 & 14 & 7 & 90 & 51 & 22 & 11 & 6 & 90 & 48 & 23 & 12 & 7 & 90 & 49 & 25 & 9 & 7 & 90 \\
\hline
\end{tabular}

(75.0\%) and the lowest to $200 \mu \mathrm{m}$ voxel size $(60 \%)(\mathrm{P}=0.411)$. In this group, the highest sensitivity belonged to 250 and $300 \mu \mathrm{m}$ voxel sizes (100\%) and the lowest to $200 \mu \mathrm{m}$ voxel size $(97.3 \%)(P=0.916)($ Table 4$)$.

In the apical third of the buccal surfaces of the roots, the highest specificity belonged to $300 \mu \mathrm{m}$ voxel size (100\%) and the lowest to 150 and $200 \mu$ m voxel sizes (93.8\%) $(\mathrm{P}=0782)$. In this group, the highest sensitivity belonged to $300 \mu \mathrm{m}$ voxel size (97.6\%) and the lowest to 150 and $250 \mu \mathrm{m}$ voxel sizes $(90.5 \%)(\mathrm{P}=0.775)$ (Table 4$)$.

In the middle third of the buccal surfaces of the roots, the specificity of 200,250 and $300 \mu \mathrm{m}$ voxel sizes was equal (88.9\%) and the specificity of $150 \mu \mathrm{m}$ voxel size was 77.8\% (P $=0.591)$. In this group, the highest sensitivity belonged to $150 \mu \mathrm{m}$ voxel size (98.8\%) and the sensitivity of other voxel sizes was equal $(97.5 \%)(\mathrm{P}=0.976)$ (Table 4$)$.

No significant differences were noted in terms of sensitivity and specificity of different voxel sizes for detection of variable-size root resorption defects.

Agreement of diagnoses with the gold standard in 150 , 200,250 , and $300 \mu \mathrm{m}$ voxel sizes for variable-size defects in the cervical, middle and apical thirds of buccal and lingual surfaces are shown in Tables 1 and 2.

\section{Discussion}

Halting the progression of defects by early treatment plays a fundamental role in the prognosis of teeth with invasive cervical (19) or inflammatory (20) root resorption defects. Therefore, early and accurate detection of root resorption can significantly increase the treatment success. 
Table 2. Agreement of Diagnoses with the Gold Standard Based on the Size of Defects in the Lingual Root Surfaces Using Different Voxel Sizes

\begin{tabular}{|c|c|c|c|c|c|c|c|c|c|c|c|c|c|c|c|c|c|c|c|c|c|}
\hline \multirow{4}{*}{$\begin{array}{l}\text { Anatom- } \\
\text { ical } \\
\text { Part }\end{array}$} & \multirow{4}{*}{$\begin{array}{c}\text { Diag- } \\
\text { nosed } \\
\text { De- } \\
\text { fect } \\
\text { Size }\end{array}$} & \multicolumn{20}{|c|}{ Voxel Size } \\
\hline & & \multicolumn{5}{|c|}{$300 \mu \mathbf{m}$} & \multicolumn{5}{|c|}{$250 \mu \mathrm{m}$} & \multicolumn{5}{|c|}{$200 \mu \mathbf{m}$} & \multicolumn{5}{|c|}{$150 \mu \mathbf{m}$} \\
\hline & & \multicolumn{20}{|c|}{ Gold Standard Defect Size } \\
\hline & & $\begin{array}{l}\text { No } \\
\text { De- } \\
\text { fect }\end{array}$ & $\begin{array}{l}\text { Small } \\
\text { De- } \\
\text { fect }\end{array}$ & $\begin{array}{c}\text { Medium } \\
\text { De- } \\
\text { fect }\end{array}$ & $\begin{array}{l}\text { Large } \\
\text { De- } \\
\text { fect }\end{array}$ & Total & $\begin{array}{c}\text { No } \\
\text { De- } \\
\text { fect }\end{array}$ & $\begin{array}{l}\text { Small } \\
\text { De- } \\
\text { fect }\end{array}$ & $\begin{array}{c}\text { Medium } \\
\text { De- } \\
\text { fect }\end{array}$ & $\begin{array}{l}\text { Large } \\
\text { De- } \\
\text { fect }\end{array}$ & Total & $\begin{array}{l}\text { No } \\
\text { De- } \\
\text { fect }\end{array}$ & $\begin{array}{l}\text { Small } \\
\text { De- } \\
\text { fect }\end{array}$ & $\begin{array}{c}\text { Medium } \\
\text { De- } \\
\text { fect }\end{array}$ & $\begin{array}{l}\text { Large } \\
\text { De- } \\
\text { fect }\end{array}$ & Total & $\begin{array}{c}\text { No } \\
\text { De- } \\
\text { fect }\end{array}$ & $\begin{array}{l}\text { Small } \\
\text { De- } \\
\text { fect }\end{array}$ & $\begin{array}{c}\text { Medium } \\
\text { De- } \\
\text { fect } \\
\end{array}$ & $\begin{array}{l}\text { Large } \\
\text { De- } \\
\text { fect }\end{array}$ & Total \\
\hline \multirow{5}{*}{$\begin{array}{l}\text { Cervical } \\
\text { Third }\end{array}$} & $\begin{array}{l}\text { No } \\
\text { de- } \\
\text { fect }\end{array}$ & 13 & 1 & 0 & 0 & 14 & 10 & 2 & 0 & 2 & 14 & 12 & 0 & 0 & 2 & 14 & 9 & 2 & 1 & 2 & 14 \\
\hline & $\begin{array}{l}\text { Small } \\
\text { de- } \\
\text { fect }\end{array}$ & 1 & 14 & 1 & 0 & 16 & 0 & 15 & 1 & 0 & 16 & 0 & 15 & 1 & 0 & 16 & 1 & 13 & 1 & 1 & 16 \\
\hline & $\begin{array}{l}\text { Medium } \\
\text { de- } \\
\text { fect }\end{array}$ & 2 & 7 & 21 & 0 & 30 & 2 & 9 & 19 & 0 & 30 & 2 & 5 & 23 & 0 & 30 & 2 & 11 & 17 & 0 & 30 \\
\hline & $\begin{array}{l}\text { Large } \\
\text { de- } \\
\text { fect } \\
\end{array}$ & 1 & 0 & 1 & 28 & 30 & 0 & 0 & 1 & 29 & 30 & 0 & 1 & 1 & 28 & 30 & 0 & 1 & 0 & 29 & 30 \\
\hline & Total & 17 & 22 & 23 & 28 & 90 & 12 & 26 & 21 & 31 & 90 & 14 & 21 & 25 & 30 & 90 & 12 & 27 & 19 & 32 & 90 \\
\hline \multirow{5}{*}{$\begin{array}{l}\text { Middle } \\
\text { Third }\end{array}$} & $\begin{array}{l}\text { No } \\
\text { de- } \\
\text { fect }\end{array}$ & 10 & 0 & 0 & 3 & 13 & 11 & 2 & 0 & 0 & 13 & 11 & 1 & 1 & 0 & 13 & 10 & 3 & 0 & 0 & 13 \\
\hline & $\begin{array}{c}\text { Small } \\
\text { de- } \\
\text { fect } \\
\end{array}$ & 0 & 28 & 1 & 1 & 30 & 0 & 27 & 2 & 1 & 30 & 0 & 28 & 1 & 1 & 30 & 1 & 26 & 2 & 1 & 30 \\
\hline & $\begin{array}{l}\text { Medium } \\
\text { de- } \\
\text { fect }\end{array}$ & 1 & 3 & 21 & 0 & 25 & 0 & 5 & 19 & 1 & 25 & 0 & 9 & 15 & 1 & 25 & 0 & 9 & 15 & 1 & 25 \\
\hline & $\begin{array}{c}\text { Large } \\
\text { de- } \\
\text { fect } \\
\end{array}$ & 0 & 0 & 1 & 21 & 22 & 0 & 1 & 0 & 21 & 22 & 0 & 0 & 1 & 21 & 22 & 0 & 0 & 1 & 21 & 22 \\
\hline & Total & 11 & 31 & 23 & 25 & 90 & 11 & 35 & 21 & 23 & 90 & 11 & 38 & 18 & 23 & 90 & 11 & 38 & 19 & 22 & 90 \\
\hline \multirow{5}{*}{$\begin{array}{l}\text { Apical } \\
\text { Third }\end{array}$} & $\begin{array}{l}\text { No } \\
\text { de- } \\
\text { fect }\end{array}$ & 42 & 0 & 0 & 0 & 42 & 39 & 1 & 2 & 1 & 43 & 39 & 1 & 1 & 1 & 42 & 39 & 1 & 1 & 1 & 42 \\
\hline & $\begin{array}{c}\text { Small } \\
\text { de- } \\
\text { fect } \\
\end{array}$ & 1 & 16 & 2 & 0 & 19 & 1 & 18 & 0 & 0 & 19 & 2 & 16 & 1 & 0 & 19 & 1 & 17 & 1 & 0 & 19 \\
\hline & $\begin{array}{l}\text { Medium } \\
\text { de- } \\
\text { fect }\end{array}$ & 0 & 4 & 14 & 0 & 18 & 0 & 5 & 13 & 0 & 18 & 0 & 5 & 13 & 0 & 18 & 0 & 7 & 11 & 0 & 18 \\
\hline & $\begin{array}{c}\text { Large } \\
\text { de- } \\
\text { fect }\end{array}$ & 0 & 0 & 1 & 10 & 11 & 1 & 1 & 0 & 8 & 10 & 1 & 0 & 2 & 8 & 11 & 1 & 1 & 2 & 7 & 11 \\
\hline & Total & 43 & 20 & 17 & 10 & 90 & 41 & 25 & 15 & 9 & 90 & 42 & 22 & 17 & 9 & 90 & 41 & 26 & 15 & 8 & 90 \\
\hline
\end{tabular}

On the other hand, conventional radiographs do not provide sufficient diagnostic value and therefore, digital diagnostic systems were introduced due to their inherent advantages (21). Assessment of root resorption using CBCT is limited to patients in whom defects have been previously detected by radiographic examination and they have taken 3D scans for therapeutic purposes (12). Considering the importance of early detection of root resorption defects in increasing the treatment success rate, this study aimed to assess the effect of voxel size on the diagnostic accuracy of root resorption by CBCT.

Previous studies have shown that conventional radiography does not provide sufficient accuracy for detection of small external root resorption defects in buccal or lingual surfaces (6, 8-10). Thus, researchers have been in search for more efficient techniques for detection of external root re- sorption defects. In 2007, Da Silveira et al. evaluated the advantages of multislice CT to detect external root resorption defects and reported that this modality had a high sensitivity and specificity in detecting external root resorption defects on the buccal root surfaces (11). However, defects in the apical third of the roots were significantly more difficult to detect. On the other hand, in 2009, Liedke et al. showed that CBCT had a very high sensitivity and specificity for detection of external root resorption defects and they reported no significant difference in this regard based on the size of the defect, its position or the plane of section (16).

The current study showed that CBCT with different voxel sizes had relatively equal diagnostic efficacy in terms of sensitivity and specificity for detection of variable-size defects in different areas and surfaces of the roots and this 
Table 3. Sensitivity, Specificity, Standard Error and 95\% Confidence Interval Values for Different Voxel Sizes for Detection of Defects in the Lingual Surfaces of the Roots

\begin{tabular}{|c|c|c|c|c|c|}
\hline & Voxel Sizes, $\mu \mathbf{m}$ & Specificity, \% & Sensitivity, \% & SE & 95\% CI \\
\hline \multirow{6}{*}{ Cervical Third } & 350 & - & 97.4 & 0.01677 & $0.974 \pm 0.03355$ \\
\hline & 300 & 92.9 & - & 0.0271 & $0.920 \pm 0.0541$ \\
\hline & 300 & - & 94.7 & 0.02362 & $0.947 \pm 0.04723$ \\
\hline & 250 & - & - & - & - \\
\hline & 200 & - & 97.4 & 0.01677 & $0.94 \pm 004723$ \\
\hline & 150 & 64.3 & - & 0.0505 & $0.643 \pm 0.1010$ \\
\hline \multirow{8}{*}{ Middle Third } & 300 & 76.9 & - & 0.0444 & $0.769 \pm 0.0889$ \\
\hline & 300 & - & 98.7 & 0.01194 & $0.987 \pm 0.02388$ \\
\hline & 250 & 84.6 & - & 0.0380 & $0.846 \pm 0.0761$ \\
\hline & 250 & - & 100 & - & - \\
\hline & 200 & 84.6 & - & 0.0380 & $0.846 \pm 0.0761$ \\
\hline & 200 & - & 100 & - & - \\
\hline & 150 & 76.9 & - & 0.0444 & $0.769 \pm 0.0889$ \\
\hline & 150 & - & 98.7 & 0.01194 & $0.987 \pm 0.02388$ \\
\hline \multirow{6}{*}{ Apical Third } & 300 & 100 & - & - & - \\
\hline & 300 & - & 97.9 & 0.01511 & $0.979 \pm 0.03023$ \\
\hline & 250 & 92.2 & - & 0.0271 & $0.920 \pm 0.0541$ \\
\hline & 200 & 92.2 & - & 0.0271 & $0.920 \pm 0.0541$ \\
\hline & 200 & - & 93.8 & 0.0254 & $0.938 \pm 0.05084$ \\
\hline & 200 & 92.2 & - & 0.0271 & $0.920 \pm 0.0541$ \\
\hline
\end{tabular}

Abbreviations: SE, standard error; CI, confidence interval.

technique had sufficient diagnostic value for detection of external root resorption. Although small differences in sensitivity and specificity were found in $150,200,250$, and $300 \mu \mathrm{m}$ voxel sizes, they were not significant.

The results of the current study are in line with those of Liedke et al. in 2009. They also reported equal specificity and sensitivity values for different CBCT voxel sizes. However, they only evaluated defects on buccal root surfaces and used iCAT CBCT system (16). In 2010, Kamburoglu et al. evaluated two CBCT systems with different voxel resolutions for detection of external and internal root resorption defects and showed that high resolutions of both systems had similar efficacy for detection of internal root resorption defects and their efficacy was superior to that of low resolutions in one of the systems (18). In addition, the results showed that the diagnostic accuracy of different voxel sizes of CBCT increased as the size of defects increased, but no significant difference was found between small and medium-size defects. In 1998, Goldberg et al. evaluated the detection accuracy of simulated external root resorption defects in the maxillary incisors and showed that detection of small defects was more difficult than that of medium and large size defects. This result was in accord with our findings (9). In 2007, Da Silveira et al. evaluated the diagnostic accuracy of CBCT for detection of external root resorption defects and showed accurate detection of apical small resorption defects in $28.6 \%$, medium-size defects in $86.66 \%$, and large defects in $100 \%$ of cases. The diagnostic accuracy of CT was higher for larger defects (11). Moreover, in 2009, Hahn et al. used flat panel volumetric CT (fpVCT) and showed that non-cavitary defects were accurately diagnosed in $53 \%$ of cases. Small resorption defects were accurately diagnosed in $69 \%$ of cases. These values were $96 \%$ for medium size and $89 \%$ for severe, large defects (22). In 2012, Neves et al. evaluated external root resorption using different voxel sizes of CBCT and showed that by an increase in size of defects, the accuracy, sensitivity, positive predictive value and negative predictive value of diagnoses increased as well $(23,24)$.

In order to three dimensionally reconstruct images using data retrieved from the axial scans, each initial voxel must be dimensionally converted to several cubic voxels. 
Table 4. Sensitivity, Specificity, Standard Error and 95\% Confidence Interval Values for Different Voxel Sizes for Detection of Defects in the Buccal Surfaces of the Roots

\begin{tabular}{|c|c|c|c|c|c|}
\hline & Voxel Sizes, $\mu \mathbf{m}$ & Specificity, \% & Sensitivity, \% & SE & 95\% CI \\
\hline \multirow{4}{*}{ Cervical Third } & 300 & - & 100 & - & - \\
\hline & 250 & - & 100 & - & - \\
\hline & 200 & 60 & - & 0.0516 & $0.60 \pm 0.1033$ \\
\hline & 200 & - & 97.3 & 0.01709 & $0.973 \pm 0.03417$ \\
\hline \multirow{5}{*}{ Middle Third } & 300 & 100 & - & - & - \\
\hline & 300 & - & 97.6 & 0.01613 & $0.976 \pm 0.03227$ \\
\hline & 250 & - & 90.5 & 0.03091 & $0.905 \pm 0.06182$ \\
\hline & 200 & 93.8 & - & 0.0254 & $0.938 \pm 0.0508$ \\
\hline & 150 & - & 90.5 & 0.03091 & $0.905 \pm 0.06182$ \\
\hline \multirow{8}{*}{ Apical Third } & 300 & 88.9 & - & 0.0331 & $0.889 \pm 0.0662$ \\
\hline & 300 & - & 97.5 & 0.01646 & $0.975 \pm 0.03291$ \\
\hline & 250 & 88.9 & - & 0.0331 & $0.889 \pm 0.0662$ \\
\hline & 250 & - & 97.5 & 0.01646 & $0.975 \pm 0.03291$ \\
\hline & 200 & 88.9 & - & 0.0331 & $0.889 \pm 0.0662$ \\
\hline & 200 & - & 97.5 & 0.01646 & $0.975 \pm 0.03291$ \\
\hline & 150 & 77.8 & - & 0.0438 & $0.778 \pm 0.0876$ \\
\hline & 150 & 98.8 & - & 0.0114 & $0.988 \pm 0.0229$ \\
\hline
\end{tabular}

Abbreviations: SE, standard error; CI, confidence interval.

This process, called interpolation, creates same-size cubic voxels that occupy the same volume. The CT number of these cubes is equal to the mean initial voxel CT number. Creation of these new cubic voxels allows image reconstruction at each surface with no reduction in resolution.

Use of CBCT, depending on the device model and the protocol applied, significantly decreases the patient radiation dose (25). Similarly, radiation dose has a direct correlation with the number of slices. Thus, it has been suggested that minimum number of slices should be used for diagnostic purposes (14). Based on the results of the current study, all three voxel sizes had almost equal diagnostic efficacy and accuracy for detection of external root resorption defects. Thus, $300 \mu \mathrm{m}$ voxel size, with the least patient radiation dose and the shortest scanning time compared to other voxel sizes may provide sufficient diagnostic accuracy for external root resorption defects in the buccal and lingual root surfaces.

Advent of CBCT revolutionized dental imaging because with only a slight increase in the patient radiation dose, high level of diagnostic information with adequate quality and quantity is obtained compared to conventional radiography and in most cases, this slight increase in dose is justifiable by taking into account the value of diagnostic information obtained. However, if this imaging modality cannot significantly increase the detection accuracy, this increase in patient radiation dose is not accepted. The patient radiation dose in CBCT scans is 3-7 times higher than that of conventional radiography. Moreover, $\mathrm{CBCT}$ is time consuming. But, the patient radiation dose in dental CBCT is much lower than that of medical CT.

On the other hand, the diagnostic advantages of each imaging technique must be considered by taking into account the risk of exposure to excess radiation. This is particularly important in younger patients since excess radiation adversely affects the development of organs (25). According to Farman in 2005, the "as low as reasonably achievable" (ALARA) principle is a fundamental rule for diagnostic radiographies that also applies to $\mathrm{CBCT}$ and some new principles must also be added for СВCТ (26). At the same time, clinicians should try to minimize the patient radiation dose without negatively affecting the quality of images. Future studies are required to compare the diagnostic accuracy of different CBCT systems for detection of external root resorption as well as other defects.

The main limitation of this study was its in vitro design; thus, generalization of results to the clinical setting must be done with caution. 

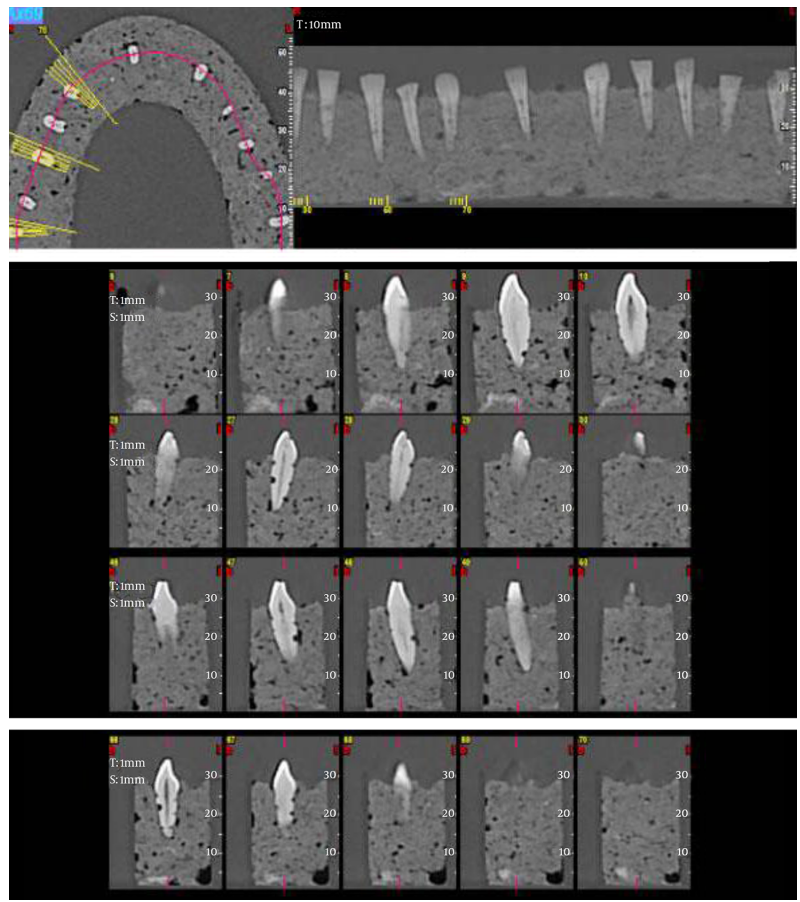

Figure 3. Sagittal, frontal, and axial sections of CBCT scans taken with four different voxel sizes of $150,200,250$ and $300 \mu \mathrm{m}$

\section{Acknowledgments}

This study was supported by a financial grant from Shahid Beheshti University of Medical Sciences.

\section{Footnotes}

Authors' Contributions: Solmaz Valizadeh was responsible for study concept and design. Acquisition of data, analysis and interpretation of data were performed by Anahita Javanmard. Drafting of the manuscript and critical revision of the manuscript for important intellectual content were done by Leila Alibakhshi. Sima Nikneshan was responsible for statistical analysis and study supervision. Administrative, technical, and material support was performed by Sima Nikneshan, Solmaz Valizadeh, and Anahita Javanmard.

Funding/Support: This study was supported by a financial grant from Shahid Beheshti University of Medical Sciences.

\section{References}

1. Bakland LK. Root resorption. Dent Clin North Am. 1992;36(2):491-507. [PubMed: 1572510].
2. Ericson S, Bjerklin K, Falahat B. Does the canine dental follicle cause resorption of permanent incisor roots? A computed tomographic study of erupting maxillary canines. Angle Orthod. 2002;72(2):95-104. doi: 10.1043/0003-3219(2002)072<0095:DTCDFC>2.0.CO;2. [PubMed: 11999943].

3. Fuss Z, Tsesis I, Lin S. Root resorption-diagnosis, classification and treatment choices based on stimulation factors. Dent Traumatol. 2003;19(4):175-82. [PubMed: 12848710].

4. Spin-Neto R, Gotfredsen E, Wenzel A. Impact of voxel size variation on CBCT-based diagnostic outcome in dentistry: a systematic review. J Digit Imaging. 2013;26(4):813-20. doi: 10.1007/s10278-012-9562-7. [PubMed: 23254628].

5. Kim E, Kim KD, Roh BD, Cho YS, Lee SJ. Computed tomography as a diagnostic aid for extracanal invasive resorption. $J$ Endod. 2003;29(7):463-5. doi: 10.1097/00004770-200307000-00009. [PubMed: 12877264].

6. Nance RS, Tyndall D, Levin LG, Trope M. Diagnosis of external root resorption using TACT (tuned-aperture computed tomography). Endod Dent Traumatol. 2000;16(1):24-8. [PubMed: 11202852].

7. Abella F, Morales K, Garrido I, Pascual J, Duran-Sindreu F, Roig M. Endodontic applications of cone beam computed tomography: Case series and literature review. Giornale Italiano Endodonzia. 2015;29(2):3850. doi: 10.1016/j.gien.2015.08.002.

8. Andreasen FM, Sewerin I, Mandel U, Andreasen JO. Radiographic assessment of simulated root resorption cavities. Endod Dent Traumatol. 1987;3(1):21-7. [PubMed:3471513].

9. Goldberg F, De Silvio A, Dreyer C. Radiographic assessment of simulated external root resorption cavities in maxillary incisors. Endod Dent Traumatol. 1998;14(3):133-6. [PubMed: 9863423].

10. Borg E, Kallqvist A, Grondahl K, Grondahl HG. Film and digital radiography for detection of simulated root resorption cavities. Oral Surg Oral Med Oral Pathol Oral Radiol Endod. 1998;86(1):110-4. [PubMed: 9690255].

11. da Silveira HL, Silveira HE, Liedke GS, Lermen CA, Dos Santos RB, de Figueiredo JA. Diagnostic ability of computed tomography to evaluate external root resorption in vitro. Dentomaxillofac Radiol. 2007;36(7):393-6. doi: 10.1259/dmfr/13347073. [PubMed: 17881597].

12. Cohenca N, Simon JH, Mathur A, Malfaz JM. Clinical indications for digital imaging in dento-alveolar trauma. Part 2: root resorption. Dent Traumatol. 2007;23(2):105-13. doi: 10.1111/j.16009657.2006.00546.x. [PubMed: 17367458].

13. Swennen GR, Schutyser F, Barth EL, De Groeve P, De Mey A. A new method of 3-D cephalometry Part I: the anatomic Cartesian 3-D reference system. J Craniofac Surg. 2006;17(2):314-25. [PubMed: 16633181].

14. Scarfe WC, Farman AG, Sukovic P. Clinical applications of conebeam computed tomography in dental practice. J Can Dent Assoc. 2006;72(1):75-80. [PubMed: 16480609].

15. Torres MG, Campos PS, Segundo NP, Navarro M, Crusoe-Rebello I. Accuracy of linear measurements in cone beam computed tomography with different voxel sizes. Implant Dent. 2012;21(2):150-5. doi: 10.1097/ID.0b013e31824bf93c. [PubMed: 22382754].

16. Liedke GS, da Silveira HE, da Silveira HL, Dutra V, de Figueiredo JA. Influence of voxel size in the diagnostic ability of cone beam tomography to evaluate simulated external root resorption. J Endod. 2009;35(2):233-5. doi: 10.1016/j.joen.2008.11.005. [PubMed: 19166780].

17. Patel S, Dawood A, Wilson R, Horner K, Mannocci F. The detection and management of root resorption lesions using intraoral radiography and cone beam computed tomography - an in vivo investigation.Int Endod J. 2009;42(9):831-8. doi:10.1111/j.1365-2591.2009.01592.x. [PubMed: 19627378].

18. Kamburoglu K, Kursun S. A comparison of the diagnostic accuracy of СВCT images of different voxel resolutions used to detect simulated small internal resorption cavities. Int Endod J. 2010;43(9):798-807. doi: 10.1111/j.1365-2591.2010.01749.x. [PubMed: 20609023].

19. Hiremath H, Yakub SS, Metgud S, Bhagwat SV, Kulkarni S. Invasive cervical resorption: a case report. J Endod. 2007;33(8):999-1003. doi 10.1016/j.joen.2007.02.014. [PubMed: 17878092]. 
20. Hommez GM, Browaeys HA, De Moor RJ. Surgical root restoration after external inflammatory root resorption: A case report. $J$ Endod. 2006;32(8):798-801. doi: 10.1016/j.joen.2005.10.038. [PubMed: 16861085].

21. Nair MK, Nair UP. Digital and advanced imaging in endodontics: a review. JEndod. 2007;33(1):1-6. doi: 10.1016/j.joen.2006.08.013. [PubMed: 17185117].

22. Hahn W, Fricke-Zech S, Fricke J, Gruber RM, Dullin C, Zapf A, et al. Detection and size differentiation of simulated tooth root defects using flat-panel volume computerized tomography (fpVCT). Oral Surg Oral Med Oral Pathol Oral Radiol Endod. 2009;107(2):272-8. doi: 10.1016/j.tripleo.2008.04.030. [PubMed:18602316].

23. Neves FS, Vasconcelos TV, Vaz SL, Freitas DQ, Haiter-Neto F. Evaluation of reconstructed images with different voxel sizes of acquisition in the diagnosis of simulated external root resorption using cone beam computed tomography. Int Endod J. 2012;45(3):234-9. doi: 10.1111/j.13652591.2011.01966.x. [PubMed: 22003884].

24. Neves FS, de Freitas DQ, Campos PS, de Almeida SM, Haiter-Neto F. In vitro comparison of cone beam computed tomography with different voxel sizes for detection of simulated external root resorption.J Oral Sci. 2012;54(3):219-25. [PubMed: 23047032].

25. Ludlow JB, Davies-Ludlow LE, Brooks SL. Dosimetry of two extraoral direct digital imaging devices: NewTom cone beam CT and Orthophos Plus DS panoramic unit. Dentomaxillofac Radiol. 2003;32(4):229-34. doi: 10.1259/dmfr/26310390. [PubMed: 13679353].

26. Farman AG. ALARA still applies. Oral Surg Oral Med Oral Pathol Oral Radiol Endod. 2005;100(4):395-7. doi: 10.1016/j.tripleo.2005.05.055. [PubMed: 16182157]. 